J. Product. \& Dev., 26(4): 1053- 1069 (2021)

\title{
EFFECT OF DIFFERENT SUBSTRATE MEDIA AND IRRIGATION ON FLOWERING AND PRODUCTION OF STRAWBERRY (Fragaria spp)
}

\author{
A. A. Hassan ${ }^{1}$; Abou El Salehein, E. H. ${ }^{I}$, M. M. El Hamady ${ }^{I}$ and M. M. \\ Sobh $^{2}$ \\ 1 - Plant Production Department, Faculty of Technological \& Development, \\ Zagazig University, Egypt \\ 2 - Soil and Water Department, Faculty of Technological Development, \\ Zagazig University, Egypt \\ e.mail: eelsalehein@yahoo.co.uk
}

\section{ABSTRACT:}

The present experiment was carried out in greenhouse during 2018/2019 and 2019/2020 seasons to determine the effects of substrates media / combination and macro and micro nutrients within irrigation water. Uniform runners of strawberry $\mathrm{cv}$. chandler were selected and planted in 12 and $13^{\text {th }}$ October 2018 and 2019 seasons, respectively, at a distance of $20 \mathrm{~cm} \times 20 \mathrm{~cm}$ in $1 \mathrm{~m} \times 1 \mathrm{~m}$ beds filled with eight different growing media combinations viz, sand (100\%), peat moss (100\%), vermiculite $(100 \%)$, perlite $(100 \%)$, peat moss: vermiculite $(50 \%$ $: 50 \%)$, peat moss : perlite (50\% :50\%), vermiculite : perlite $(50 \%$ :50\%), and peat moss: vermiculite: perlite (33.3\%: $33.3 \%: 33.3 \%)$ with three replications.The plants were irrigated at 1-2 days interval through micro drip irrigation during the initial stages and through drip irrigation during fruiting stages, while the treatments of macro and micro-nutrients dose of fertilizers were applied through fertigation using soluble fertilizers. The irrigation water was included two treatments, i.e. top water used as control, and fertilizer water which included macro and micro - nutrients, (\%) i.e. $\mathrm{N}-\mathrm{P}-\mathrm{K}-\mathrm{Ca}-\mathrm{Fe}-\mathrm{Zn}$ - B - Cu and Mn (1-2 - 2-0.3-0.1-0.2-0.1-0.2 and 0.1), respectively. The experiment was performed in the layout of split plot design, where, the substrate media was distributed at the main plot, while the irrigation water without or with fertilizers was distributed at the sub plot in three replications. 
The obtained results are summarized as follows:

The treatment of the triple media of peat moss, vermiculite and perlite, being the most effectives on plant growth parameters, i.e. plant height, number of leaves, crown diameter, canopy spread, fresh weight and dry weight of plant, flowering parameters, i.e. number of days to open $1{ }^{\text {st }}$ flower, number of flowers/plant, number of fruits/plant and fruit set (\%),yield and its components of strawberry, i.e. fruit length fruit diameter, total number of fruits/plant, fruit weight early yield and total yield, and fruit quality of strawberry, i.e. $N, P, K, C a$, TSS, acidity, vitamin $C$, total sugars and anthocyanin.This treatment followed by the treatment which contained of two substrates, i.e. vermiculite: perlite, peat moss: perlite, and peat moss: vermiculite, respectively. While, the single treatment of perlite, vermiculite and peat moss caused a lowest value with any significant between them.

The macro and micro elements within irrigation water by drip irrigation system significantly increased vegetative growth parameters of strawberry plants, i.e. plant height, number of leaves crown diameter canopy spread, fresh weight and dry weight of plants, flowering parameters, yield and it components, and fruit quality compared to the untreated plants with elements (control treatment). The combined effect of substrate media and fertilizer with macro and micro-nutrients had a significant influence on all the vegetative growth of strawberry i.e. plant height, number of leaves/plant, crown diameter, canopy spread, fresh and dry weight of plant, flowering parameters, yield and it components , and fruit quality, the treatment of interaction between the triple treatment of interaction between the triple treatment (peat moss: vermiculite and perlite) and fertilizer with macro and micro-nutrients being the most effective on vegetative growth strawberry.

Conclusively, it can be concluded that for getting to good strawberry characters using the triple substrate media together and applied different nutrients within drip irrigation .

Key words: Substrate media - drip irrigation - fertigation- strawberry.

\section{INTRODUCTION:}

Strawberry (Frag aria spp.) is one of the most popular soft fruits cultivated in plains, as well as, in the hills up to an elevation of $3000 \mathrm{~m}$ in humid or dry regions (Singh et al., 2008). Strawberry belonging to the family Rosaceae is one the most delicious, delicate flavoured, refreshing, and 
attractive red fruit of the world (Sharma, 2002). It is usually eaten as raw of used to making ice-creams, jams, jellies, pickles, chocolates, biscuits, cakes, and milkshakes. Strawberry also, rich in vitamin $\mathrm{C}$ and total antioxid- ents and are thus important for human health (Halvorsen et al., 2002). It has also a good portion of fiber, secondary metabolites and sugar. This helps to reduce the blotting problem, as well as, decrease the cardiovascular diseases.

Strawberry being a shallow rooted plant needs effective nutrient management. The soil acts as a reservoir to retain nutrients and water, and also provides physical support for the root system. The increased demand for strawberries throughout the year can be met through soilless cultivation. Soilless culture is an artificial means of providing plants with support and a reservoir for nutrients and water. Characteristics of substrates include holding water and nutrient, providing good aeration to root system, light weight, free of pathogenic organisms and substances that are toxic to plants (Johnson et al., 2010 and Ameri et al., 2012). The use of different organic and inorganic substrates allows the plants better nutrient uptake, sufficient growth and development to optimize water and oxygen holding (Albaho et al., 2009 and Ibrahimi et al., 2012).

In strawberry culture, severe production losses are caused by soil-borne diseases. Therefore, there is a trend towards using soilless media to avoid diseases (Jansen, 1997). Most growing media for strawberries are peat moss, rock wool, coir, perlite or some other mixtures. The number of leaves, runners and crown diameter in many cultivars, tike as; Camaros a, Gaviota, and Sèlva cultivars of strawberry were higher in media of peat and coco peat as compared to media with sand and perlite $100 \%$ (Tehranifar et al., 2007). The nutrients status in the strawberry plant plays a vital roles in determining the growth, chemical content, yield and quality of fruits since it is a very sensitive plant to nutritional balance (Mohamed et al., 2011).

Both macro and micro-nutrients are well known to ameliorate plant growth, chemical content, yield and quality of fruit plants, N, P, K, and Ca are of the most important macro nutrients that are increased fruit quality and shelf life, and are well documented by many investigators (Bakshi et al., 2013, and Sangeeta et al., 2019). Among various micro-nutrients, iron (Fe) and zinc (Zn) plays an important role in promoting vegetative growth, flowering, fruit yield and quality of strawberry (Chaturvedi et al., 2005).

Therefore, the objective of this study to investigate the soilless strawberry cultivation possibilities in different media and irrigate with macro and micro-nutrients on earliness, yield and quality of fruit strawberry. 


\section{MATERIALS AND METHODS}

The present experiment was carried out in greenhouse during 201812019 and 2019/2020 seasons to determine the effects of substrates/ Combination and of macro and micro nutrients within irrigation water. Uniform runners of strawberry $\mathrm{cv}$. chandler were selected and planted in 12 and $13^{\text {th }}$ October 2018 and 2019 seasons, respectively, at a distance of $20 \mathrm{~cm}$ x $20 \mathrm{~cm}$ in $1 \mathrm{~m} \mathrm{x}$ $1 \mathrm{~m}$ beds filled with eight different growing media combinations viz, send (100\%), peat moss $(100 \%)$, vermiculite $(100 \%)$, perlite $(100 \%)$, peat moss: vermiculite $(50 \%: 50 \%)$, peat moss : perlite $(50 \%: 50 \%)$, vermiculite : perlite (50\%:50\%), and peat moss: vermiculite: perlite (33.3\%: $33.3 \%: 33.3 \%)$ with three replications.

The substrates were used to create the different treatments in different proportion (by volume) for propagation, while the sand was used as control. The plants were irrigated at 1-2 days interval through micro sprinkler irrigation during the initial stages and through drip irrigation during fruiting stages, while the treatments of macro and micro-nutrients dose of fertilizers were applied through fertigation using soluble fertilizers. The irrigation water was included two treatments, i.e. top water used as control, and fertilizer water which included macro and micro - nutrients, (\%) i.e. $\mathrm{N}-\mathrm{P}-\mathrm{K}-\mathrm{Ca}-\mathrm{Fe}-\mathrm{Zn}$ $-\mathrm{B}-\mathrm{Cu}$ and $\mathrm{Mn}(1-2-2-0.3-0.1-0.2-0.1-0.2$ and -0.1$)$, respectively. The fertigation system was open drip irrigation with no circulation, using 1 liter/hour capacity inline lateral drippers installed on each plot for the treatments fertilized.

\section{Data recorded:}

Flowering and fruit set: at 180 days after plating.

No. of days to open $1^{\text {st }}$ flower,

No. of flower/plant, fruit set (\%),

No. of fruits and fruit weight $(\mathrm{g})$,

\section{Chemical constituents of fruits (The nutritive value):}

Acidity (\%), TSS (\%), vitamin C (\%), total sugars (\%), Anthocyanin (mg/100g F.w), N , P, K and Ca.

\section{Fruit yield and its components:}

Length of fruit $(\mathrm{cm})$, fruit weight ( $\mathrm{g} / \mathrm{plant})$, total number of fruits/plant, fruit diameter $(\mathrm{cm})$, early yield (g/plant) and total early yield $(\mathrm{g} / \mathrm{plant})$ and total yield $(\mathrm{kg})$. 
The weight of the fruit, were measured by using Sartorius balance with accuracy of $0.001 \mathrm{~g}$. The length and diameter of each quince genotype was measured by digital Vernier caliper. The fruit total soluble solids (TSS) were determined by using hand refractometer. Titratable acidity was determined by macerating $10 \mathrm{~g}$ of fruit sample in distilled water. The pulp was filtered through muslin cloth and made up to $10 \mathrm{ml}$ with distilled water and $5 \mathrm{ml}$ of filtrate was titrated against standard $\mathrm{NaOH}$ using phenolphthalein indicator. The value was expressed in terms of malic acid as per cent Titratable acidity (measured by a method as reported by The Association of Official Analytical Chemists (AOAC. 2012).

Fruit quality parameters: Total soluble solids contents in fruit were analyzed by Hand refractometer and averaged from five fruits in each replication. These total soluble solids (TSS) contents were analyzed at room

temperature by following the method mentioned by AOAC (1990). Ascorbic acid contents were determined from randomly selected five fruits per replication using spectrophotometer (OPTIMA, SP-3000-plus). Fruit pulp from selected plants was mixed with $5 \mathrm{ml}$ of $0.1 \%$ hydrochloric acid. This mixture was subjected to centrifugation process for ten minutes at 10,000 rpm speed. The absorbance at 243 nanometer wavelength was documented. Titratable acidity recorded through titration method at fruit ripening stage (Hans, 1992) using the following formula:

Titratable acidity $(\%)=[(\mathrm{m} \times 0.064) / 10] \times 100$

In the above formula $m$ denotes Burette reading, Determine the content of total sugars and nonsugar content), organic acids - by titration with phenolphthalein (PN-90/A-75101/04. and anthocyanins - using spectrophotometry method (Wrolstad, 1993), and N, P , K and Ca. according to the methods described by ( A. O .A. C.,2012).

\section{Statistical analysis:}

The experiment was performed in the layout of split plot design, where, the substrate media was distributed at the main plot, while the irrigation water without or with fertilizers was distributed at the sub plot. The significant difference were calculated employing analysis of variance (A nova) and statistical lettering was done using Least Significant Difference (LSD) system of comparison at 5\% probability level (Snedecor and Cochran, 1989). SAS (2004) software was used for data analysis. 


\section{RESULTS AND DISCUSSION:}

\section{Flowering:}

\section{Effect of different substrate media :}

Concerning the effect of the different media on Flowering parameters, i.e. number of days to open $1^{\text {st }}$ flowers number of flowers/plan, number of fruits/plant and fruit set (\%), data in Table (1) indicated that all these parameters under investigation gave a significant difference among the values of these parameters. The maximum value of all these parameters were executed for the treatment of the triple substrate media (peat moss: vermiculite: perlite), followed by the treatment of vermiculite: perlite.

The properties of different materials used as soilless growing media exhibit direct and indirect effects on raising the flowering of strawberry plants (Rabeer et al., 2013). These results sustained those recorded by Maher et al. (2020). They illustrated that the number of days to open first flowers was maximum under perlite $(50 \%)+$ FYM $(50 \%)+$ jeevamrit.

\section{Effect of macro and micro- nutrients :}

Data in Table (1) indicated that irrigation of strawberry plants with macro and micro- nutrients, i.e. $\mathrm{N}, \mathrm{P}, \mathrm{K}, \mathrm{Ca}, \mathrm{Fe}, \mathrm{Zn}, \mathrm{Mu}, \mathrm{Cu}$, and $\mathrm{B}$, significantly increased the mean values of all the parameters of flowering as compared with the control treatment under this study.

Respecting the role of macro and micro- nutrients used in this study, many investigators, concluded that these elements had a vital role direct and indirect in activation flowering of strawberries (Chaturvedi et al., 2005 and Chandrakar et al., 2018). The obtained results of confirmed with those of Bakshi et al., (2013), Kasemi (2014) and Singh et al., (2015). They noted that macro elements improved the flowing of strawberry plants.

\section{Yield and its components: \\ Effect of substrate media}

Data in Tables (2 and 3 ) manifested that the different substrate media as soilless substrates significantly increased the fruit yield and its components of strawberry the triple substrate media (peat moss: vermiculite: perlite) had a maximum values on yield and its components of strawberry, i.e. fruit length, fruit diameter, total number of fruits/plant, fruit weight, early yield and total yield.

Respecting the important role of substrate media in improving the fruit yield of strawberry, Inden and Torres (2004) pointed out that the difference 
materials of soilless sub rates has aerial porosity and better capacity of water and nutrient maintenance and it has high water absorption and oxygen holding and allows the plants better for sufficient growth, development and increases the fruit yield (Hesami et al., 2012, Ayesha et al., 2011 and Raja et al., 2018). These results followed the same patterns of Itani et al., (1999), Paranipe et al., (2003 and 2008), Medina et al., (2009), Adak and Gubbuk (2015) and Maher et al., (2020).

\section{Effect of macro and micro- nutrients :}

Data presented in Tables (2 and 3) clearly reveal that irrigation the plants with $\mathrm{N}, \mathrm{P}, \mathrm{K}, \mathrm{Ca}, \mathrm{Fe}, \mathrm{Zn}, \mathrm{Mu}, \mathrm{Cu}$ and $\mathrm{B}$ had a simulative effect of fruit yield and its components of strawberry.

The increase in fruit yield may be directly due to the increase in growth parameters and flowering practices (Table 1) and number and weight of fruit (Table 2).

Comparable results were also detected by Sangeeta et al. (2019), Mishra et al. (2016) and Chandrakar et al. (2019).

\section{Fruit quality (The nutritive value): Effect of substrate media:}

Data given in Tables (4 and 5) show that different substrate media had a marked effect on fruit quality of strawberry, i.e. N, P, K, Ca, TSS , acidity, vitamin $\mathrm{C}$, total sugars and anthocyanin. The treatment of the triple substrate media, $i . e$. peat moss, vermiculite and perlite significantly increased all the contents of fruit quality of strawberry, followed by vermiculite + perlite and peat moss + perlite treatment, respectively.

Regarding the effect of substrate media on fruit quality, Albaho et al., (2009) and Ebrahimi et al., (2012) concluded that the different substrate media allows the plants better nutrient uptake, sufficient growth and development to optimize water and oxygen holding Moreover, using soilless media avoid diseases (Jansen, 1997), then increased the quality of fruit. These results are in harmony with those found by Tehranifar et al., (2007) and Mohamed et al., (2011).

\section{Effect of macro and micro nutrients:}

Data in Tables ( 4 and 5 ) show that all parameters of the fruit chemical constituents (the nutritive value) were significantly increased with applied macro and micro nutrients within irrigation water (fertigation) in both growth seasons. The increment in the chemical constituents of strawberry fruits was 
obtained when plants received fertilizer level from $1 \mathrm{~N}, 2 \mathrm{P}, 2 \mathrm{~K}, 0.3 \mathrm{Ca}, 0.1$ $\mathrm{Fe}, 0.2 \mathrm{Zn}, 0.2 \mathrm{Cu}$, and $0.1 \mathrm{~B}$ (percentages).

These elements plays a vital role in the photosynthetic activity, biochemical and biological processes in tissues of different parts of plant consequently, increased the nutrients and compounds of fruits (Sangeeta et al., ,2019). These results were in conformity with those recorded by Bakshi et al., (2013), Kumar et al., (2012) and Sangeeta et al., (2019).

Conclusively, it can be concluded that for getting to good strawberry characters using the triple substrate media together and applied different nutrients within drip irrigation .

\section{REFERENCES}

Adak N, I Tozlu, and H Gubbuk. 2018. Influence of different soilless substrates to morpho-physiological characteristics and yield relations in strawberries. Erwerbs-Obstbau p. 1-8.

Adak, N., and H. Gubbuk .2015. Effect of planting systems and growing media on earliness, yield and quality of strawberry cultivation under soilless culture. Not Bot Horti Agrobo, 43(1):204-209.

Ameri A., A.Tehranifar, M.Shoor,and G. H.Davarynejad 2012.Effect of substrate and cultivar on growth characteristic of strawberry in soilless culture system. African Journal of Biotechnology, 11 (56): 11960-11966.

AOAC .1990. Official Methods Of Analysis. Association of analytical chemists. $15^{\text {th }}$ edition, Virginia,Arlington, USA. 12-98 pp.

AOAC. 2012. Official Methods of Analysis. Association of Official and Analytical Chemists, $17^{\text {th }}$ ed.; Gaithersburg, Md, USA.

Ayesha R, N Fatima, M Ruqayya, H Faheem, KM Qureshi, and IA Hafiz .2011. Influence of different growth media on the fruit quality and reproductive growth parameters of strawberry (Fragaria $\times$ ananassa). Journal of Medicinal Plants Research, 5(26):6224-6232.

Bakshi, P., A. Jasrotia, V.K. Wali, A. Sharma, and M.Akshi (2013). Influence of pre-harvest application of calcium and micro-nutrients on growth, yield, quality and shelf-life of trawberry cv "Chandler". Ind. J. Agric. Sci.83:831-835. 
Chandrakar S., P Singh, HK Panigrahi,and P. Sarita .2018. Effect of foliar spray of calcium and micro-nutrients on growth parameters, flowering, fruiting and fruit maturity of strawberry (Fragaria $\mathrm{x}$ ananassa Duch.) cv. Nabila under net tunnel. J. of Pharmacognosy and Phytochemistry, 7(6):5-10.

Chandrakar S., P. Singh, HK Panigrahi, P. and A. Kumar. 2019. Response of foliar application of micro-nutrients on number of flowers, fruits and yield per plant of strawberry (Fragaria $\mathrm{x}$ ananassa Duch.) cv. Nabila under net tunnel condition. The Pharma Innovation, 8(4):531533.

Chaturvedi, O.P., A.K. Singh, V.K. Tripathi, and A.K. Dixit .2005. Effect of zinc and iron on growth, yield and quality of strawberry $c v$. "Chandler". Acta. Hort. 696:237-240.

Ebrahimi R., M. K Souri., F Ebrahimi., and M Ahmadizadeh. 2012. Growth and yield of strawberries under different potassium concentrations of hydroponic system in tree substrates. World Applied Sciences Journal, 16 (10): 1380-1386.

Farid M. Z., K. M. Qureshi, S. H. Shah, A. A. Qureshi, M. Umair and H. Shafiq .2020. Foliar application of micronutrients improves growth ,productivity and fruit quality of strawberry (Fragaria ananassa duch). Journal of Animal \& Plant Sciences, 30(4): 2020, Page: 905-912.

Hans, Y.S.H. 1992. The guide book of food chemical experiments. Pekin Agricultural University Press, Pekin.

Hesami A, SS Khorami, and AB Kashkooli. 2012. Date-peat as an alternative in hydroponic strawberry production. African Journal of Agricultural Research. 7(23):3452-3458.

Itani, Y., T. Hara, N. W. Phun, Y.Fujime, and Y. Yoshida. 1999. Effects of $\mathrm{CO}_{2}$ enrichment and planting density on the yield, fruit quality and absorption of water and mineral nutrients in strawberry grown in peat bag culture. Environ. Control in Biol. 37(3): 171-177.

Jansen, W. A. G. M. 1997. Growing media and plant densities for strawberry tray plants. Acta Hort., 439: 457-460.

Johnson Jr. H, GJ Hochmuth, and DN Maynard. 2010. Soilless culture of greenhouse vegetables. Institute of Food and Agricultural Sciences. University of Florida.; 218:19-22.

Kazemi M. 2014 .Influence of foliar application of iron, calcium and zinc sulfate on vegetative growth and reproductive characteristics of strawberry cv. 'pajaro' Trakia. Journal of Sci.; 1:21-26. 
Kumar, S.S., K. Pramod, K. Mahesh, S. Saravanan, M.L.Choudhary, and M.C. Sharma .2012).. Studies on influence of bio-fertilizers and micronutrients on growth, flowering and yield of strawberry(Fragaria $x$ ananassa Duch) cv. "Chandler" Ann. Hortic. 5:259-264.

Maher MM, Bunty Shylla, DD Sharma and U. Sharma.2020. Influence of different soilless substrates and jeevamrit on flowering and fruiting behaviour of strawberry (Fragaria $\mathrm{X}$ ananassa Duch.) cv. Chandler. Journal of Pharmacognosy and Phytochemistry, 9(4): 428-432

Mishra AK, S. Kumar, S. Verma, SK Dubey, and AK Dubey. 2016. Effect of zinc sulphate, boric acid and iron sulphate on vegetative growth, yield and quality of strawberry (Fragaria x ananassa. Duch.) cv. Chandler. The Bioscan and International Quarterly Journal of Life Science, 11(4):2222-2225.

Mohamed RA, HA Abd El-Aal, and MG Abd El-Aziz. .2011. Effect of phosphorus, zinc and their interactions on vegetative growth characters, yield and fruit quality of strawberry. J of Hort. Sci. and Orna. Plants, 3(2):106-114.

Muhammad R. and U. S. Qureshi. 2013. Effect of planting density and growing media on growth and yield of strawberry. Pakistan J. Agric. Res. Vol. 26 No. 2 ,

Paranipe AV, DJ Cantliffe, PI Stoffell EM A Lamb,and Ca.Powell .2008. Relationship of plant density to fruit yield of 'Sweet Charlie' strawberry grown in a pine bark soilless medium in a high-roof passively ventilated greenhouse. Scientia Horticulturae, 115(2): 117-123.

Rabeea T., Kh. M.Qureshi, I. Hassan, M. Rasheed, and U. Sh. Qureshi .2013. Effect of planting density and growing media on growth and yield of strawberry. Pakistan J. Agric. Res. 26 (2):1-9.

Raja, Wasim H, KL Kumawat, OC Sharma, A. Sharma, JI Mir, UN Sajad Nabi, S. Lal and I. Qureshi (2018). Effect of different substrates on growth and quality of Strawberry cv. chandler in soilless culture . Pharma Innovation Journal 7(12): 449-453

Sangeeta, HK Panigrahi, Y. Lodhi and M. Saha (2019). Growth, yield and quality improvement in strawberry through foliar application of calcium, iron and zinc: A review. Journal of Pharmacognosy and Phytochemistry; 8(6): 734-737

Sharma, R.R. 2002. Growing Strawberries.International Book Distributing Co. Chaman Studio Building, 2nd Floor, Charbagh, Lucknow 226004 U.P. (India). p. 164. 
Singh R, RR Sharma, S Kumar, RK Gupta, and RT Patil.2008. Vermicompost substitution influences the physiological disorders, fruit yield and quality of strawberry (Fragaria $\times$ ananassa Duch). J. Biore. Tech.; 99: 8507-8511.

Singh, M., M. Jamwal, N. Sharma, R. Kumar, and V. Wali .2015. Response of iron and zinc on vegetative and reproductive growth of strawberry (Fragaria $\times$ ananassa Duch.) $c v$. Chandler. Bangladesh $J$. Bot. 44(2):337-340.

Tehranifar, A., M. Poostchi, H. Arooei, and H. Nematti. 2007. Effects of seven substrates on qualitative and quantitative characteristics of three strawberry cultivars under soilless culture. Acta Hort. 761: 485-488.

Wrolstad R. E. 1993. Color and pigment analyses in fruit products. Agricultural Experiment Station of Oregon State University, Station Bulletin No. 624, 17 p.

\section{تأثير بيئات الزراعة المختلفة والري علي إزهار وانتاج الفراولة}

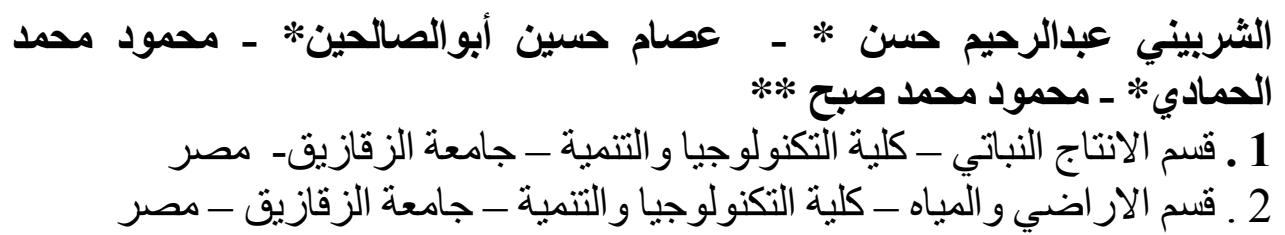

اجريت التجربة في الصوبة خلال موسمي 2019/2018 ، 2019/ 2020 لتقدير

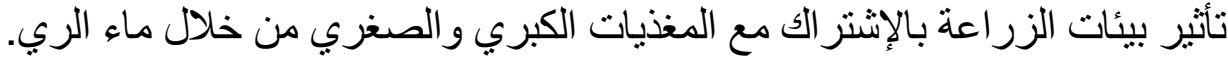

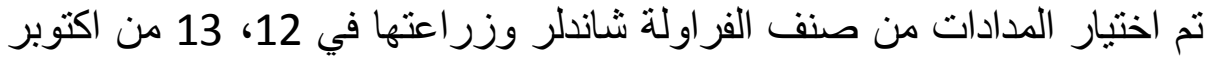

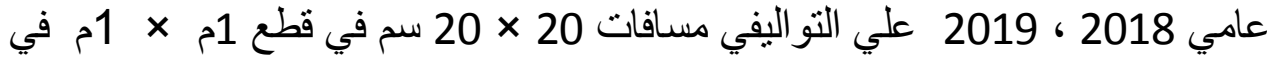

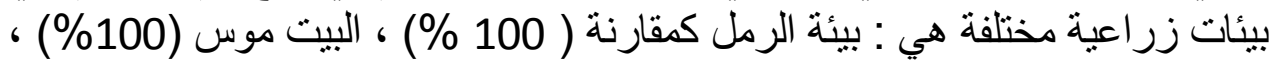

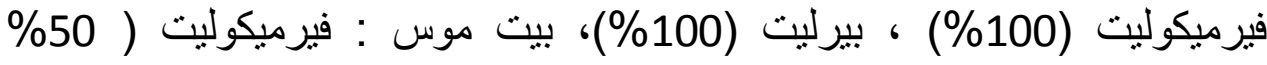
\%50:

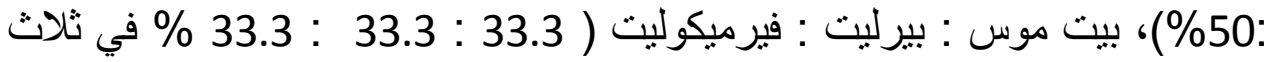

$$
\text { مكررات . }
$$

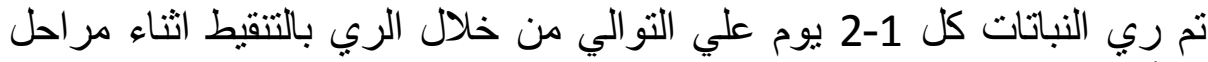

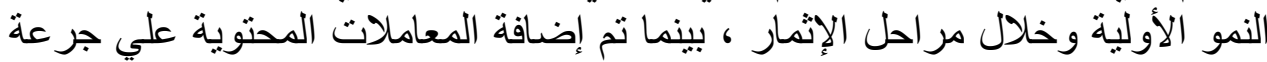
المغذيات الكبري و الصغري من خلال إذابتها في ماء الري الري. 
اشتنطل ماء الري علي معاملتين هما الري بماء الصنور كماملة المقارنة ، الري الري

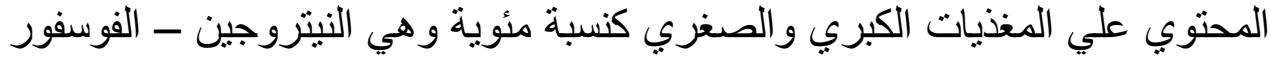

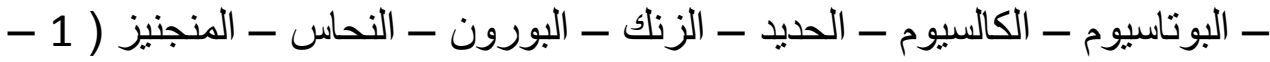

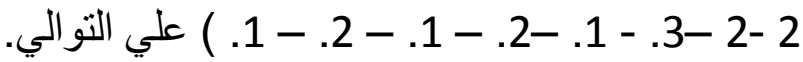

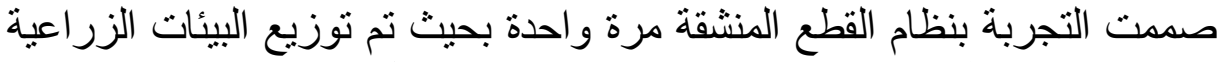

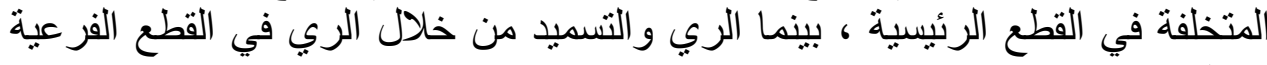

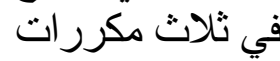

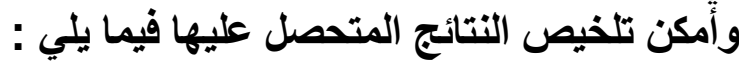

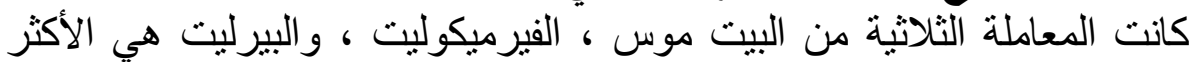

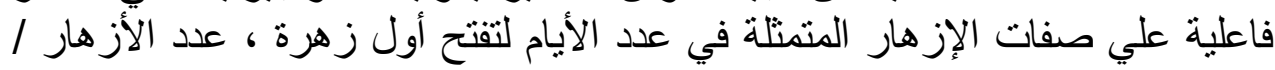

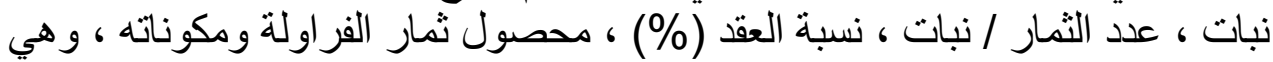

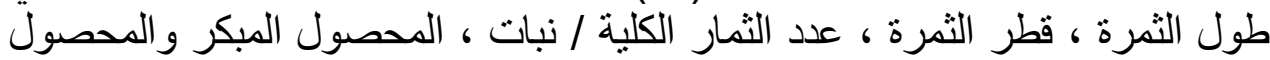

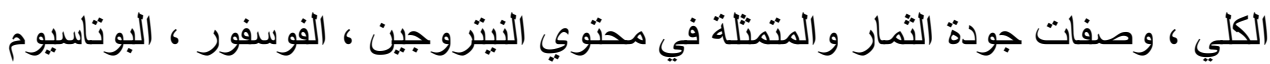

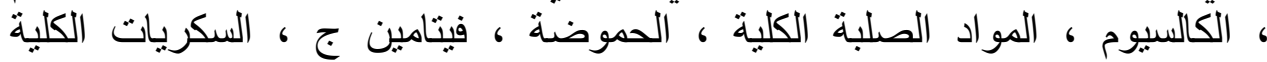
و الأنثوسيانين

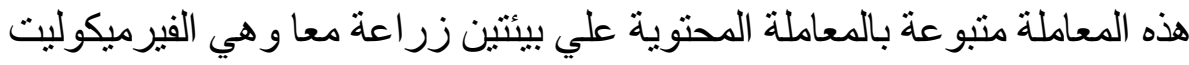

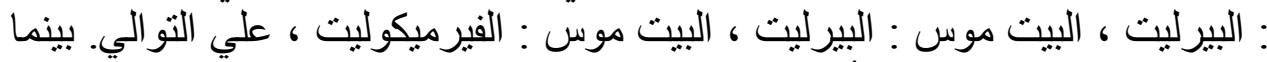

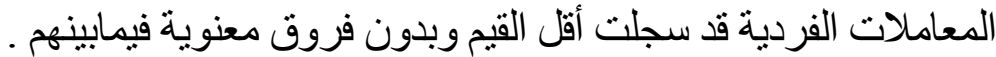

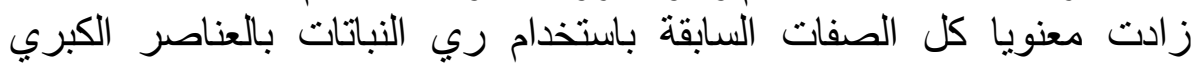

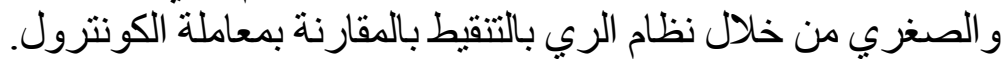

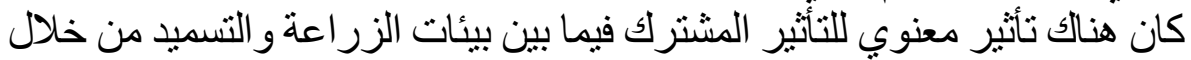

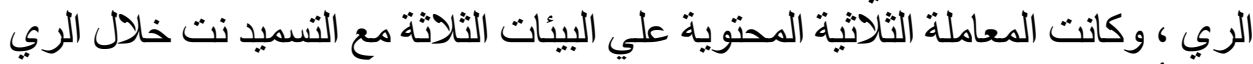

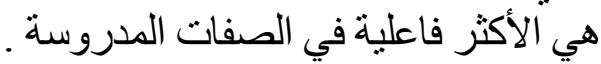

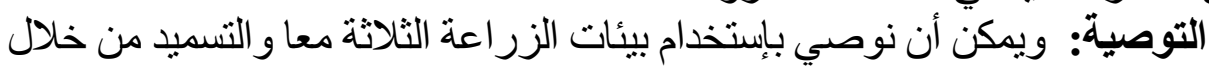

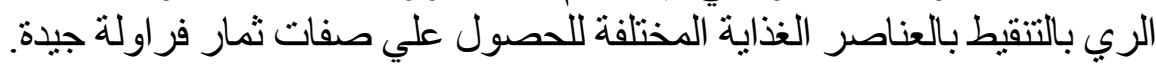


